\title{
Resource aware wind farm and D-STATCOM optimal sizing and placement in a distribution power system
}

\author{
Anzum Ansari ${ }^{1}$, Shankarlingappa C. Byalihal ${ }^{2}$ \\ ${ }_{1}^{1}$ Department of Electrical and Electronics Engineering (EEE), Acharya Institute of Technology, Bengaluru, India \\ ${ }^{1,2}$ Department of Electrical and Electronics Engineering (EEE), Dr. Ambedkar Institute of Technology, Bengaluru, India
}

\begin{tabular}{|c|c|}
\hline Article Info & ABSTRACT \\
\hline Article history: & Doubly fed induction generators (DFIG) based wind farms are capable of \\
\hline Received Oct 14, 2020 & $\begin{array}{l}\text { providing reactive power compensation. Compensation capability } \\
\text { enhancement using reactors such as distributed static synchronous }\end{array}$ \\
\hline Revised May 20, 2021 & compensator (D-STATCOM) while connecting distribution generation (DG) \\
\hline Accepted Jun 8, 2021 & $\begin{array}{l}\text { systems to grid is imperative. This paper presents an optimal placement and } \\
\text { sizing of offshore wind farms in a coastal distribution system that is emulated }\end{array}$ \\
\hline Keywords: & $\begin{array}{l}\text { on an IEEE } 33 \text { bus system. A multi-objective formulation for optimal } \\
\text { placement and sizing of the offshore wind farms with both the location and }\end{array}$ \\
\hline Distribution generator & size constraints is developed. Teaching learning algorithm is used to optimize \\
\hline D-STATCOM & $\begin{array}{l}\text { the multi-objective function constraining on the capacity and location of the } \\
\text { offshore wind farms. The proposed formulation is a multi-obiective problem }\end{array}$ \\
\hline Optimal placement & for placement of the wind generator in the power system with dynamic wind \\
\hline Optimal sizing & supply to the power system. The random wind speed is generated as the input \\
\hline Wind farm & $\begin{array}{l}\text { and the wind farm output generated to perform the optimal sizing and } \\
\text { placement in the distributed system. MATLAB based simulation developed } \\
\text { is found to be efficient and robust. }\end{array}$ \\
\hline
\end{tabular}

This is an open access article under the CC BY-SA license.

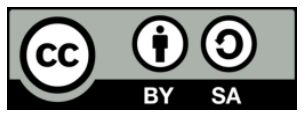

\section{Corresponding Author:}

Anzum Ansari

Department of Electrical and Electronics Engineering

Acharya Institute of Technology

Bengaluru, India

Email: anzumansari@gmail.com

\section{INTRODUCTION}

With 7200 kilometers of the coastal region, India has the capability of installing offshore wind farms ranging to around $70 \mathrm{GW}$ and above. Optimal placement and sizing of DGs for minimized loss and higher reliability using discrete particle swarm optimization (DPSO) is developed on a semi-urban 37 bus distribution system [1]. Multi distributed generation (DG) placement and sizing adopting particle swarm optimization (PSO) based multi-objective optimization considering loading in the line, active and reactive power loss, voltage profile, and MVA intake by the grid as the parameters [2]. Distributed network operators (DNO) and the distributed generation owners (DGO) invest in the equipment in a different way. Optimal sizing and placement of DG that acts as the tradeoff between both their investments for a planning period are developed [3]. A two-stage heuristic method is applied to obtain the benefit-sharing between both DNO and DGO. Voltage stability margin improvement by introducing renewable energy to voltage sensitive buses is formulated using mixed-integer nonlinear programming [4]. Improved multi-objective harmonized system (IMOHS) and non-dominated sorting genetic algorithm II (NSGA-II) algorithms are compared for the optimal placement and sizing of DG. Power loss and voltage profile are considered as the multiobjective function for convergence [5]. Kalman filter-based algorithm that chooses the optimal size of the DG in steps 
of $10 \mathrm{KW}$ is applied on a 60 mega volt ampere (MVA) scale distribution network. Optimal locator index is introduced to determine the power loss sensitivities and to adopt the best location of the DG [6]. A multiobjective formulation that includes minimizing the number of DGs and maximizing voltage stability is applied for DG placement and sizing problem. Nonlinear programming is applied to the multiobjective problem and shown better efficiency [7]. A multiobjective approach for DG sizing and placement is developed for an IEEE 33 bus system that benefits both the DG owners and distribution companies. It uses PSO algorithm to optimize both operational and generation-based parameters [8]. A non-iterative method for DG sizing and placing that gives the output directly is developed [9]. According to the sensitivity factors, a priority list is developed and executed to give a quick solution for the sizing and placement problem. An improved nondominated sorting genetic algorithm-II (INSGA-II) is developed for the sizing and placement of DGs [10]. Recently the popularity of the offshore wind farm is evident with the research findings on uniform wind speed and large sea area in the offshore environment. Both medium voltage alternating current (MVAC) and medium voltage direct current (MVDC) distribution system's performance is evaluated for the offshore wind farms [11]. Direct load flow solution with the kirchoff voltage law (KVL) and kirchoff current law (KCL) is implemented with offshore wind farms in the distribution system and the performance evaluation is carried out. Anticipating the inherent voltage instability due to the squirrel cage induction generator (SCIG) a DG configuration that combines both the SCIG and DFIG is used to solve the voltage instability issue. The IEEE 1547 standard that standardizes the connection of distributed energy resources (DERs) to the main grid describes that the unity power factor needs to be maintained. This literature has a setup that would allow the DFIG to absorb the reactive power that is fed by the SCIG to the grid thus paving the way to follow IEEE 1547 standards [12]. Optimal sizing and placement of flexible air conditioning transmission system (FACTS) devices and renewable distributed generators with varying and stable renewable energy input is discussed in literatures [13]-[18]. New contribution from the conventional approaches is proposed in [19], which is the scenario reduction algorithm unlike the cost reduction algorithm due to voltage unstability. Instead of the cost reduction algorithm that reduces the cost of power production due to voltage unstability, this implementation concentrates on voltage unstability reduction which is called the scenario reduction algorithm. The constraints of availability of the wind generation in the bus need to be constrained for an in situ scenario. Previous publications dealing with the placement of the wind generation system has allowed the constant wind generation system as the DG in the placement problem. Dynamics of the wind speed variation need to be adopted in the placement of the wind generator.

This paper provides the placement of the wind generation system by formulating the wind placement system by calculating the probabilistically variable wind generation in only a few selected buses. A multiobjective sizing and placement of DG and D-STATCOM are combined in the solution that is implemented on an IEEE 33 bus distributed system. This paper proposes the multiobjective objective function with benefit to cost ratio obtained from ration, maintenance cost, and nvestment cost. The multiobjective formulation also includes network security index and the voltage safety factor. The paper is organized in the following manner. Section 2 discusses the multiobjective formulation that includes the voltage stability as well as the cost-based constraint. Section 3 discusses the results and discussion of the optimization framework, followed by a conclusion and references.

\section{PROBLEM FORMULATION}

The primary contriution of this paper is obtaining the placement of the wind generation system with multiobjective function that include, cost security, and safety of the network. Dynamic wind veariation is considered as the DG in this formulation. The problem is formulated to minimize the total cost of wind power generation and maintenance. In the total cost, there are three parts. Investment cost (IC), operation, and maintenance cost (OMC) of DG including the interest rate and inflation rate are considered. The benefits of cost due to the placement of DG are considered along with the benefit to cost ratio (BCR). This has to be maximum so that the benefits are more while maintaining the voltage stability factor (VSF) and network security index within the limit. Formulation of the multiobjective problem is is being as, the size of the wind turbine generator is calculated by using (1) with wind velocity as the input. For determining the output power of the wind turbines, the annual average speed is considered as $6.02 \mathrm{~m} / \mathrm{s}$.

$$
\begin{gathered}
P_{\text {rated }}=0.5 \rho A v_{w}^{3} C_{p} \\
P_{D G \text { ren }}=\left\{\begin{array}{c}
0 V<V_{\text {cin }} \text { or } V_{w}>V_{\text {out }} \\
P_{\text {rated }}\left(V_{w}-V_{\text {cin }}\right) /\left(V_{N}-V_{\text {cin }}\right) V_{-} \text {cin } \leq V_{-} w \leq V_{-} N \\
P_{\text {rated }} V_{N} \leq V_{w} \leq V_{\text {cout }}
\end{array}\right.
\end{gathered}
$$


Here, $P_{\text {rated }}-$ is the total $D G$ power required $V_{w}-$ wind velocity in $\frac{m}{s}, \quad V_{\text {cin }}-$ cutin $\operatorname{speed~in~} \frac{m}{s}$, $V_{\text {cout }}-$ cutout speed in $\frac{m}{s}, V_{N}$ - nominal speed in $\frac{m}{s}, c_{p}$ Performance coefficient of the turbine, $\rho$ Air density $\left(\mathrm{kg} / \mathrm{m}^{3}\right)$, A - Turbine swept area $\left(\mathrm{m}^{2}\right)$.

- The total cost of renewable DGs due to installation, operation and maintenance is given in (3) with the maintenance, interest, and BCR components.

$$
\text { Cost }_{D G \text { ren }}=\sum_{i=2}^{N} \sum_{j \in t y p e} I C_{i j} * n_{i} * l_{i}+\left(\sum_{i=2}^{N} \sum_{j \in t y p e} O M C_{i j} * P_{D G \text { ren } i j} * n_{i} * l_{i}\right) * C P V
$$

Where

$$
\begin{aligned}
& I C_{i j}-\text { Ivestment cost type ' } j{ }^{\prime} \text { renewable DGat bus ' } i{ }^{\prime} \\
& O M C_{i j} \text { - Operation and maintenance cost of type'j'renewable DGat bus ' } i \text { ' } \\
& n_{i} \text { - number of DG unit connected at the bus ' } i \text { ' } \\
& l_{i}-\text { location variable at bus ' } i{ }^{\prime}(0 \text { or } 1) \\
& P_{D G \text { ren } i j}-\text { Power generated by type ' } j \text { 'DG at the bus ' } i{ }^{\prime} \\
& N-\text { number of buses in the network } \\
& \text { CPV - cumulative present value } \\
& C P V=\frac{\left(1-P V^{N y}\right)}{(1-P V)}
\end{aligned}
$$

Here, The present value of cost

$$
P V=\frac{1+\frac{I F}{100}}{1+\frac{I R}{100}}
$$

Where, -Inflation rate, IR - interest rate and $N_{y}-$ Number of year in the planning horizon

- In (6) defines the overall benefits that is obtained by introducing the renewable DGs in the distribution network.

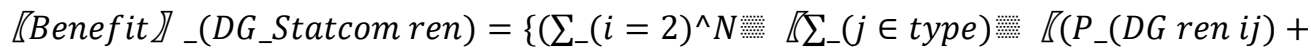

$$
\begin{aligned}
& \left.\left.\left.Q_{-}(\text {Statcom ren } i j)\right) * n_{-} i \rrbracket * l_{-} i\right)+\rrbracket \Delta \text { 《Ploss } \rrbracket_{-}(D G \text { ren })\right\} * C_{-} h r * 8760 * C P V(6)
\end{aligned}
$$

Where, $\Delta$ Ploss $_{D G \text { ren }}-$ Power loss due to allocation of renewable DGs,

$$
C_{h r}-\text { Cost of electricity }
$$

Here $\mathrm{C} 2$ is statcom cost. Qst is the reactive power placed in at the bus in MVAR. The benefit to cost ratio $\mathrm{BCR}$ is given in (8).

$$
\begin{aligned}
& C 2\left(Q_{S T}\right)=\frac{1000 X Q_{S T}}{8760 X 15}\left(0.0002466 Q_{S T}^{2}-0.2243 Q_{S T}+150.527\right) \\
& B C R_{D G \text { ren }}=\frac{\text { Benefit }_{D G_{-} S T A T C O M \text { ren }}}{\text { Cost }_{D G \text { ren }}}
\end{aligned}
$$

- Voltage stability factor

Voltage stability factor (VSF) in any bus due to the introduction of DG placement in any line of the distribution network is defined in equation (9), for $\mathrm{i}+1$ th bus. 


$$
V S F_{i+1}=\left(2 V_{i+1}-V_{i}\right)
$$

Where, $V_{i}$-voltage magnitude at bus $i, V_{i+1}$-voltage magnitude at bus $i+1$ and VSF for the entire network is given by.

$$
V S F=\frac{\sum_{i=1}^{N-1} V S F_{i+1}}{(N-1)}
$$

- Network security index

Security of the network also should be considered on the placement of DG.

$$
L L_{i}=\frac{L_{M V A, i}}{L_{M V A_{\max , i}}}
$$

Network security index can be formulated as given in (12).

$$
N S I=\frac{\sum_{i=1}^{N-1} L L_{i}}{(N-1)}
$$

Certain buses can't use wind energy as it has the complexity in connecting the wind turbine in that location neglecting few buses using the following equation.

$$
\begin{aligned}
& B_{\text {feasibile }, i} \leq \text { Optimal location }<B_{\text {infeasible }, i} \\
& \text { here } i-\text { index of the } B_{\text {feasible }} \& B_{\text {infeasible }}
\end{aligned}
$$

Similarly,

$$
\begin{aligned}
& \text { total demand in } M V A=\sum_{i=1}^{n} \sqrt{ }\left(P_{D i}^{2}+Q_{D i}^{2}\right) \\
& 0 \leq \text { Optimal size }<\text { total demand in } M V A
\end{aligned}
$$

A low value is better. So, the objective function is represented as.

$$
\text { minimize }\left(P_{D G \text { ren } i j}, n_{i}, l_{i}\right)=\left(1+\left(\frac{1}{B C R}\right)\right)+\left(1+\frac{1}{V S F}\right)+N S I+\frac{P_{\text {loss }_{\text {without }}}}{P_{\text {loss }_{\text {with }}}}
$$

In the formulation, the wind generation cost is taken from [20]. The (14) defines the objective function that needs to be minimized using the metaheuristic methods. The convergence of both the PSO and teaching-learning-based optimization (TLBO) algorithm will follow this objective function which includes both the voltage stability and cost parameters in it. The IEEE 33 bus distributed system is used to validate the problem formulation and the results and discussion obtained are as explained in the next section.

\section{TEACHER AND LEARNER ALGORITHM}

This algorithm is made of the teacher-learning ability of the teacher and student in a classroom. The TLBO algorithm is divided into two parts. Teacher phase and Learner phase. The population (control variable/the parameters need to be identified) $\mathrm{X}$ is randomly initialized. The search space is of $N \times D$. The $\mathrm{N}$ is the number of learners and $\mathrm{D}$ is the course offered. This is the problem dimension. The iteration count $\left(I T_{\max }\right)$ is the total number of iteration carried out and this is the stopping criteria. By defining the size of the DG (in Wattage), STATCOM location (line number) and number of DG as the independent variables and considering the equation (14) as the objective function TLBO algorithm is applied to obtain the best of the DG size, STATCOM location and number of DGs. Optimization algorithm that runs for few number of iterations is executed and results are obtained using the algorithm similar with modified objective function and condition of wind energy resources availability. The multiple objectives like the benefit to cost ratio (BCR), voltage stability factor (VSF), network security index, and loss minimization are considered. The $\mathrm{BCR}$ and VSF are maximized with minimization of losses and network service integration (NSI) is carried out. 


\section{RESULTS AND DISCUSSION}

Wind DGs are placed in the IEEE 33-bus radial distribution system with 33 buses in the implementation using MATLAB. Total load size of 3.715 MW and 2.3 MVar with $12.66 \mathrm{kV}$. As the grid standards the lower and upper limit 0.95 p.u and 1.05 p.u respectively. Here the DG is considered as the wind turbine connected with the DFIG generatorThe multi-objective function is tested with PSO and TLBO algorithm. The wind data used in the solution is as given in Table 1. The wind data is selected with a random generation of wind as the nature of wind daily cannot be predicted exactly. According to [20], [21] average of 6.06 is assumed for calculations. The algorithm is run many times and tested for robustness.

Table 1. Wind data considered [21], [22]

\begin{tabular}{cc}
\hline Parameters & Values \\
\hline Wind available buses & 2 to 16 \\
wind not available buses & 17 to 33 \\
Cut-in speed in $\mathrm{m} / \mathrm{s}$ & 6 \\
Cutout speed in $\mathrm{m} / \mathrm{s}$ & 13 \\
Wind velocity considered in $\mathrm{m} / \mathrm{s}$ & $6.06[21],[22]$ \\
Air density in $\mathrm{kg} / \mathrm{m}^{2}$ & 1.225 \\
$\mathrm{C}_{\mathrm{F}}$ & 0.59 \\
Length of the wing $(\mathrm{m})$ & $52 \mathrm{~m}$ \\
\hline
\end{tabular}

The problem thus formulated in the previous section stipulates the placement of the wind buses in the buses mentioned as "wind available buses" in the above table. The constraint also extends to the amount of power generated in each bus in the wind buses. The formulation is optimized using both the PSO and TLBO algorithms [23]-[25]. The (14) is defined as the objective function and is minimized for better placement and sizing of the DG.

The curve of convergence for both the PSO and the TLBO based optimal sizing and placement is as shown in Figure 1. The convergence of the TLBO exhibits earlier convergence and with lesser cost than the PSO algorithm. Since the STATCOM placement also is combined for the DG placement in the implementation the voltage stability is assured in the buses. TLBO algorithm is giving better fitness by minimizing the cost objective function. Observing the convergence graph in Figure 2 indicates that the TLBO converged at the $13^{\text {th }}$ iteration and PSO at the $50^{\text {th }}$ iteration. A slightly better voltage profile is observed in the TLBO algorithm compared to the PSO algorithm as is shown in Figure 1.

Table 2 exhibits voltage stability in all the buses with DG and the STATCOM placement is optimized using both PSO and the TLBO algorithm. It is also evident from Table 2 that the voltage stability improvement is better with TLBO algorithm when compared to the PSO algorithm. The cost of the wind generation for calculation is obtained from [22]. Although the PSO and TLBO algorithms are applied for the placement and sizing in different peaces of literature literatures [23]-[25].

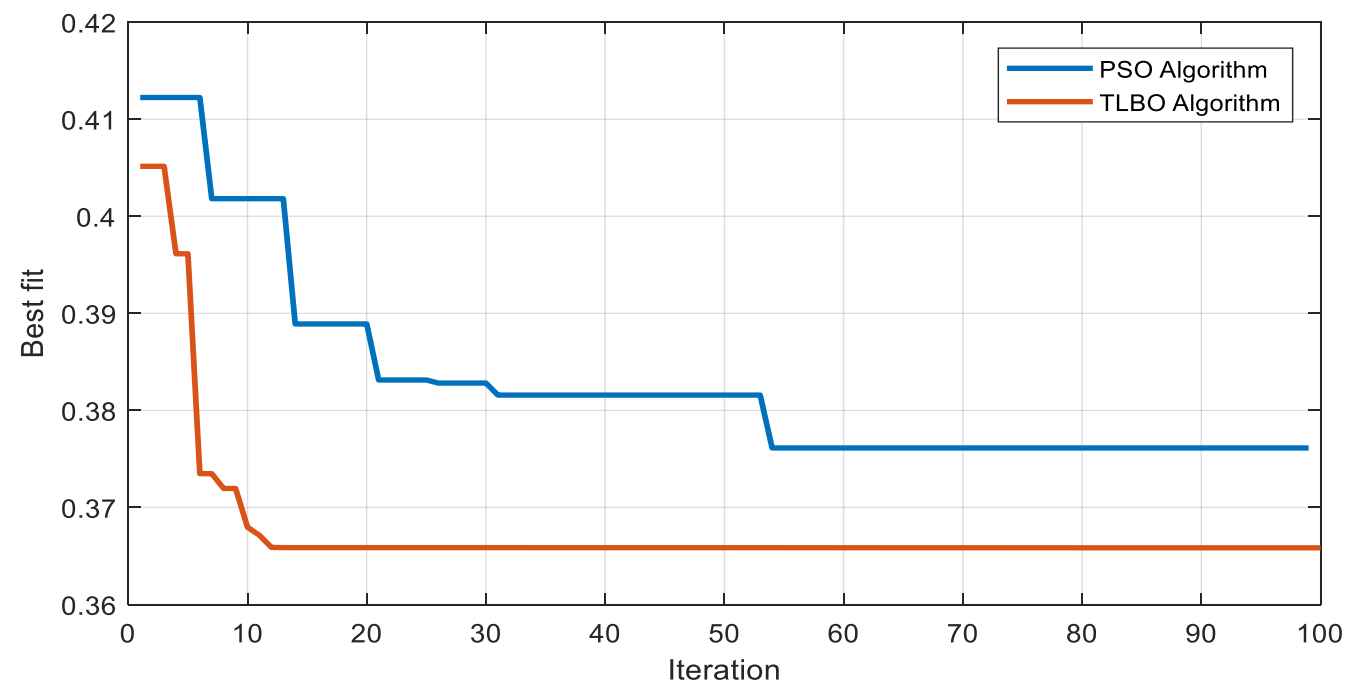

Figure 1. Convergence waveform of TLBO and PSO 


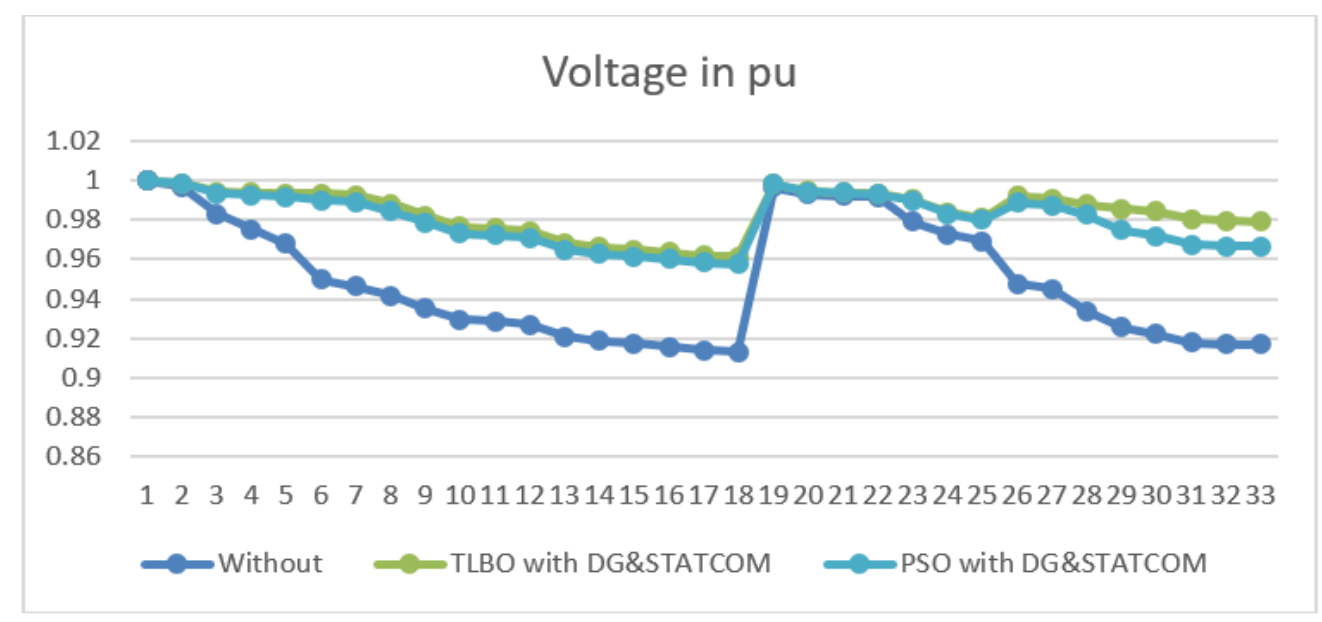

Figure 2. Voltage profile of the base case, PSO and TLBO

Table 2. Voltage values in per unit (pu)

\begin{tabular}{|c|c|c|c|}
\hline \multicolumn{4}{|c|}{ Voltage in pu } \\
\hline Bus no. & Without & TLBO & PSO \\
\hline & DG and DSTATCOM & with DG \& STATCOM & with DG \& STATCOM \\
\hline 1 & 1 & 1 & 1 \\
\hline 2 & 0.9970 & 0.9988 & 0.9986 \\
\hline 3 & 0.9829 & 0.9942 & 0.9934 \\
\hline 4 & 0.9754 & 0.9937 & 0.9924 \\
\hline 5 & 0.9680 & 0.9936 & 0.9918 \\
\hline 6 & 0.9497 & 0.9933 & 0.9900 \\
\hline 7 & 0.9462 & 0.9927 & 0.9892 \\
\hline 8 & 0.9414 & 0.9881 & 0.9846 \\
\hline 9 & 0.9351 & 0.9821 & 0.9786 \\
\hline 10 & 0.9293 & 0.9766 & 0.9731 \\
\hline 11 & 0.9284 & 0.9758 & 0.9722 \\
\hline 12 & 0.9269 & 0.9743 & 0.9708 \\
\hline 13 & 0.9208 & 0.9685 & 0.9650 \\
\hline 14 & 0.9185 & 0.9664 & 0.9628 \\
\hline 15 & 0.9171 & 0.9650 & 0.9615 \\
\hline 16 & 0.9157 & 0.9637 & 0.9601 \\
\hline 17 & 0.9137 & 0.9618 & 0.9582 \\
\hline 18 & 0.9131 & 0.9612 & 0.9576 \\
\hline 19 & 0.996 & 0.9982 & 0.9981 \\
\hline 20 & 0.9929 & 0.9947 & 0.9945 \\
\hline 21 & 0.9922 & 0.9940 & 0.9938 \\
\hline 22 & 0.9915 & 0.9933 & 0.9932 \\
\hline 23 & 0.9793 & 0.9906 & 0.9898 \\
\hline 24 & 0.9726 & 0.9840 & 0.9832 \\
\hline 25 & 0.9693 & 0.9807 & 0.9799 \\
\hline 26 & 0.9477 & 0.9923 & 0.9889 \\
\hline 27 & 0.9451 & 0.9911 & 0.9874 \\
\hline 28 & 0.9337 & 0.9877 & 0.9828 \\
\hline 29 & 0.9255 & 0.9855 & 0.9750 \\
\hline 30 & 0.9219 & 0.98427 & 0.9716 \\
\hline 31 & 0.9178 & 0.9803 & 0.9677 \\
\hline 32 & 0.9169 & 0.9795 & 0.9668 \\
\hline 33 & 0.9166 & 0.9792 & 0.9665 \\
\hline
\end{tabular}

Table 3 depicts the location and sizing of the DG and also the indexes defined in the formulation, The TLBO exhibits better index values either it is the voltage-based index or the cost-based indexes. The placement and sizing of the DG and D-STATCOM placement are better with the TLBO algorithm in all the indexes and the loss and cost values. The size of DG placed using the TLBO algorithm is $2.2577 \mathrm{MW}$ and the D-STATCOM is of 1.2502 mega volt ampere reactive (MVAR). The size of DG placed using the PSO algorithm is $2.1421 \mathrm{MW}$ and the D-STATCOM is of 1.058 MVAR. The fitness function that is proportional to the cost is 0.3664 units with the TLBO algorithm as compared to 0.3761 units with the PSO algorithm. Using TLBO the fitness minimizes $2.57 \%$. 
The cost objective is lesser with the TLBO algorithm compared to the PSO algorithm. This improves the VSF by $0.44 \%$, NSI by $0.43 \%$, and the total loss minimized by $13.35 \%$. These all happen when the BCR of the nearly the same value. So, without compromizing the cost of the STATCOM the improvements are done in the test system considered. The proposed multi-objective formulation with dynamic wind speed input clearly improves the fitness while the TLBO algorithm is implemented. From table it is evident that the TLBO algorithm dominates in every aspect of the multi-objective formulation proposed. Thus, the multi-objective formulation with dynamic wind generation input is found to be working effectively with good voltage stability and network security.

Table 3. Convergence results of TLBO and PSO

\begin{tabular}{ccc}
\hline \multirow{2}{*}{ Parameters } & TLBO & PSO \\
\cline { 2 - 3 } & with DG \& STATCOM & with DG \& STATCOM \\
\hline Fit & 0.3664 & 0.3761 \\
BCR & 2.7700 & 2.7846 \\
VSF & 0.9826 & 0.9783 \\
NSI & 0.4345 & 0.4330 \\
Loss in KW & 52.8162 & 60.9530 \\
Location & 7,30 & 7,28 \\
Size in MW & $2.2577,1.2502$ & $2.1421,1.058$ \\
\hline
\end{tabular}

\section{CONCLUSION}

Multi-objective placement and sizing of DG and D-STATCOM problem formulated based on the availability of the wind resources is solved using both PSO and TLBO algorithm. The stable voltage stability and cost reduction are evident in the implementation of both the metaheuristics methods. Although voltage stability is evident in both the algorithms the TLBO algorithm exhibited better convergence both in terms of improved performance indexes and also the cost minimization. Thus, the proposed multi-objective formulation has shown good performance while introducing the dynamic wind generation input. Cost, network security and the voltage safety is found optimized to obtain the optimized placement of the wind generator.

\section{REFERENCES}

[1] I. Ziari, G. Ledwich, A. Ghosh, D. Cornforth, and M. Wishart, "Optimal allocation and sizing of DGs in distribution networks," IEEE PES General Meeting, 2010, pp. 1-8, doi: 10.1109/PES.2010.5588114.

[2] A. M. El-Zonkey, "Optimal placement of multi-distributed generation units including different load models using particle swarm optimization," in IET Generation, Transmission \& Distribution, vol. 5, no. 7, pp. 760-771, July 2011, doi: 10.1049/iet-gtd.2010.0676.

[3] A. Soroudi, M. Ehsan, R. Caire, and N. Hadjsaid, "Hybrid immune-genetic algorithm method for benefit maximization of distribution network operators and distributed generation owners in a deregulated environment," in IET Generation, Transmission \& Distribution, vol. 5, no. 9, pp. 961-972, September 2011.

[4] R. S. Al Abri, E. F. El-Saadany, and Y. M. Atwa, "Optimal Placement and Sizing Method to Improve the Voltage Stability Margin in a Distribution System Using Distributed Generation," in IEEE Transactions on Power Systems, vol. 28, no. 1, pp. 326-334, Feb. 2013, doi: 10.1109/TPWRS.2012.2200049.

[5] K. Nekooei, M. M. Farsangi, H. Nezamabadi-Pour, and K. Y. Lee, "An Improved Multi-Objective Harmony Search for Optimal Placement of DGs in Distribution Systems," in IEEE Transactions on Smart Grid, vol. 4, no. 1, pp. 557-567, March 2013, doi: 10.1109/TSG.2012.2237420.

[6] S. H. Lee and J. Park, "Optimal Placement and Sizing of Multiple DGs in a Practical Distribution System by Considering Power Loss," in IEEE Transactions on Industry Applications, vol. 49, no. 5, pp. 2262-2270, Sept.-Oct. 2013, doi: 10.1109/TIA.2013.2260117.

[7] M. Esmaili, "Placement of minimum distributed generation units observing power losses and voltage stability with network constraints," in IET Generation, Transmission \& Distribution, vol. 7, no. 8, pp. 813-821, Aug. 2013, doi: 10.1049/iet-gtd.2013.0140.

[8] A. Ameli, S. Bahrami, F. Khazaeli, and M. Haghifam, "A Multiobjective Particle Swarm Optimization for Sizing and Placement of DGs from DG Owner's and Distribution Company's Viewpoints," in IEEE Transactions on Power Delivery, vol. 29, no. 4, pp. 1831-1840, Aug. 2014, doi: 10.1109/TPWRD.2014.2300845.

[9] S. Elsaiah, M. Benidris, and J. Mitra, "Analytical approach for placement and sizing of distributed generation on distribution systems," in IET Generation, Transmission \& Distribution, vol. 8, no. 6, pp. 1039-1049, June 2014, doi: 10.1049/iet-gtd.2013.0803.

[10] W. Sheng, K. Liu, Y. Liu, X. Meng, and Y. Li, "Optimal Placement and Sizing of Distributed Generation via an Improved Nondominated Sorting Genetic Algorithm II," in IEEE Transactions on Power Delivery, vol. 30, no. 2, pp. 569-578, April 2015, doi: 10.1109/TPWRD.2014.2325938. 
[11] S. C. Raval, R. Botta, and H. N. Raval, "Comparison of energy production cost for MVAC and MVDC offshore wind farm distribution system," 2017 Asian Conference on Energy, Power and Transportation Electrification (ACEPT), 2017, pp. 1-6, doi: 10.1109/ACEPT.2017.8168543.

[12] T. M. Masaud, G. Nannapaneni, and R. Challoo, "Optimal placement and sizing of distributed generation-based wind energy considering optimal self VAR control," in IET Renewable Power Generation, vol. 11, no. 3, pp. 281288, 2017, doi: 10.1049/iet-rpg.2015.0391.

[13] S. M. Hakimi, A. Hasankhani, M. Shafie-khah, and J. P. S. Catalão, "Optimal sizing and siting of smart microgrid components under high renewables penetration considering demand response," in IET Renewable Power Generation, vol. 13, no. 10, pp. 1809-1822, July 2019, doi: 10.1049/iet-rpg.2018.6015.

[14] Z. Li, Y. Xu, S. Fang, and S. Mazzoni, "Optimal placement of heterogeneous distributed generators in a gridconnected multi-energy microgrid under uncertainties," in IET Renewable Power Generation, vol. 13, no. 14, pp. 2623-2633, October 2019, doi: 10.1049/iet-rpg.2019.0036.

[15] J. Radosavljević, N. Arsić, M. Milovanović, and A. Ktena, "Optimal Placement and Sizing of Renewable Distributed Generation Using Hybrid Metaheuristic Algorithm," in Journal of Modern Power Systems and Clean Energy, vol. 8, no. 3, pp. 499-510, May 2020, doi: 10.35833/MPCE.2019.000259.

[16] Y. Chi and Y. Xu, "Multi-stage coordinated dynamic VAR source placement for voltage stability enhancement of wind-energy power system," in IET Generation, Transmission \& Distribution, vol. 14, no. 6, pp. 1104-1113, March 2020, doi: 10.1049/iet-gtd.2019.0126.

[17] A. A. Yahaya, M. AlMuhaini, and G. T. Heydt, "Optimal design of hybrid DG systems for microgrid reliability enhancement," in IET Generation, Transmission \& Distribution, vol. 14, no. 5, pp. 816-823, January 2020, doi: 10.1049/iet-gtd.2019.0277.

[18] X. Xiong, W. Wu, N. Li, L. Yang, J. Zhang, and Z. Wei, "Risk-Based Multi-Objective Optimization of Distributed Generation Based on GPSO-BFA Algorithm," in IEEE Access, vol. 7, pp. 30563-30572, 2019, doi: 10.1109/ACCESS.2019.2902886.

[19] J. Liu, Y. Xu, J. Qiu, Z. Y. Dong, and K. P. Wong, "Non-Network Solution Coordinated Voltage Stability Enhancement with STATCOM and UVLS for Wind-Penetrated Power System," in IEEE Transactions on Sustainable Energy, vol. 11, no. 3, pp. 1559-1568, July 2020, doi: 10.1109/TSTE.2019.2931455.

[20] Saidah and M. Masrufun, "Optimization of DG Placement and Size Using PSO Based on GUI," 2020 International Conference on Smart Technology and Applications (ICoSTA), 2020, pp. 1-6, doi: 10.1109/ICoSTA48221.2020.1570615982.

[21] Windpower Engineering and Development, "How to calculate-wind-power output," 2020. [Online]. Available: https://www.windpowerengineering.com/.

[22] The Royal Academy of Engineering, "Wind Turbine Power Calculation." [Online]. Available: https://www.raeng.org.uk/publications/other/23-wind-turbine.

[23] I. Irena, "Renewable Power Generation Costs in 2017," International Renewable Energy Agency, Abu Dhabi, 2018.

[24] B. Hussain, A. Amin, A. Mahmood, and M. Usman, "An Optimal Site Selection for Distributed Generation in the Distribution Network by QPSO Algorithm," 2020 International Conference on Engineering and Emerging Technologies (ICEET), 2020, pp. 1-6, doi: 10.1109/ICEET48479.2020.9048230.

[25] G. Trivedi, A. Markana, P. Bhatt, and V. Patel, "Optimal Sizing and Placement of Multiple Distributed Generators using Teaching Learning Based Optimization Algorithm in Radial Distributed Network," 2019 6th International Conference on Control, Decision and Information Technologies (CoDIT), 2019, pp. 958-963, doi: 10.1109/CoDIT.2019.8820681.

\section{BIOGRAPHIES OF AUTHORS}

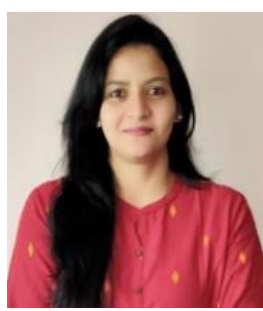

Anzum Ansari had received her B.E (Electrical) degree as a Gold Medalist from HNGU, Gujarat, India in 2010 and M. Tech (Power Systems Engineering) degree as a Gold Medalist from Visveswaraya Technological University, Belgaum, Karnataka, India in 2013. She is a research scholar of Dr. Ambedkar Institute of Technology, Bangalore and presently working as an Assistant Professor in the Department of EEE at Acharya Institute of Technology. Bangalore. Her current research area includes renewable energy, FACTs controllers, and power systems. She is a Life Member of the Indian Society for Technical Education (ISTE).

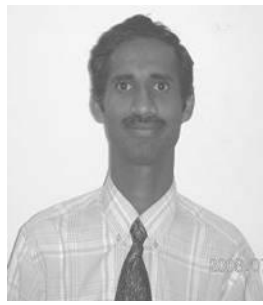

Shankaralingappa C. B. was born in Raichur, Karnataka, India on June 01, 1969. He received his B.E (Electrical) and M.E (Energy systems) degrees from Karnatak University Dharwar, India in 1993 and 94, respectively, and Ph.D. (Power Systems) from Visveswaraya Technological University, Belgaum Karnataka, India in 2011. Currently, he is working as a professor in the Department of Electrical \& Electronics Engineering at Dr. Ambedkar Institute of Technology, Bangalore. His current research interests renewable integration, electric vehicle, and metaheuristic algorithms. He is a Life Member of the Indian Society for Technical Education (ISTE). 